\title{
Simulation and Experimental Investigation of Electrochemical Trepanning of an Aero-Engine Diffuser with Different Flow Fields
}

\author{
Zhouzhi $G u^{1}$, Xiaohu Zheng ${ }^{1 *}$, Yongcheng Ge $e^{2}$ \\ ${ }^{1}$ Jiangsu Key Laboratory of Advanced Manufacturing Technology, Huaiyin Institute of Technology, \\ Huai'an 223000, China \\ ${ }^{2}$ College of Mechanical Engineering, Yangzhou University, Yangzhou 225127, China \\ *E-mail: hyzxh@126.com
}

Received: 13 June 2021 / Accepted: 20 September 2021 / Published: 10 October 2021

\begin{abstract}
The electrochemical-trepanning process is an economical approach for manufacturing diffuser structures. In the electrochemical-trepanning process, the flow field is an important factor that affects machining stability, machining efficiency, and surface quality. In this study, two different flow fields of the forward flow-field mode and the lateral flow-field mode were proposed, and their numerical models were also established and then simulated using FLUENT software. The results showed that the flow velocity of the forward flow-field mode was higher, and the flow velocity of the lateral flow-field mode was more uniform. Furthermore, a fixture was designed to realize this new flow mode, and then corresponding experiments were carried out. The experimental results illustrated that the forward flowfield mode could get a better feed speed of $2.5 \mathrm{~mm} / \mathrm{min}$, and the lateral flow-field mode could get a better surface quality of $1.581 \mu \mathrm{m}$. In addition, since the lateral flow field was more uniform, the flow pattern on the machined surface disappeared, and the machining quality was greatly improved.
\end{abstract}

Keywords: electrochemical machining; flow field; experiment; diffuser

\section{$\underline{\text { FULL TEXT }}$}

(C) 2021 The Authors. Published by ESG (www.electrochemsci.org). This article is an open access article distributed under the terms and conditions of the Creative Commons Attribution license (http://creativecommons.org/licenses/by/4.0/). 